\title{
Emodin and Its Combination with Cytarabine Induce Apoptosis in Resistant Acute Myeloid Leukemia Cells in Vitro and in Vivo
}

\author{
Yingyu Chen ${ }^{\mathrm{a}}$ Donghui Gan ${ }^{\mathrm{a}} \quad$ Qinghua Huang $^{\mathrm{b}} \quad$ Xiaofeng Luo $^{\mathrm{a}} \quad$ Donghong Linc $^{\mathrm{c}}$ \\ Jianda $\mathrm{Hu}^{\mathrm{a}}$ \\ aFujian Medical University Union Hospital, Fujian Institute of Hematology, Fujian Provincial Key

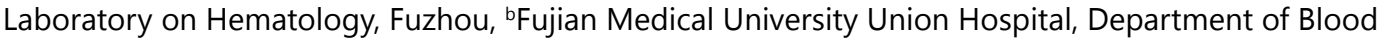 \\ Transfusion, Fuzhou, 'Fujian Medical University, School of Medical Technology and Engineering, \\ Department of Clinical Laboratory, Fuzhou, Fujian, China
}

\section{Key Words}

Emodin $\cdot$ Cytarabine $\cdot$ Acute myeloid leukemia $\bullet$ Apoptosis $\bullet$ Multidrug resistance $\cdot$ Akt/ mTOR - ERK • Xenograft model

\begin{abstract}
Background/Aims: Acute myeloid leukemia (AML) remains a hematologic malignancy with poor survival and a high risk of relapse, which is mainly caused by the emergence of multidrug resistance (MDR). The identification of novel agents to improve therapeutic strategies becomes important priority for AML treatment. It has been shown that emodin has therapeutic effects on many kinds of human malignant tumors. In this study, we investigated the anti-leukemia effects of emodin alone or in combination with cytarabine (Ara-C) on multidrug-resistant $\mathrm{AML}$ HL-60/ADR cells and in a mouse xenograft model of human highly tumorigenic AML HL-60/H3 cells. The underlying mechanism was also addressed. Methods: Cell viability after treatment was measured by MTT assay. The DNA fragmentation assay, Annexin V-PE/7-AAD, AO/EB staining, and electron microscopy were introduced to assess the apoptotic induction effects. Changes in protein expression in the Akt and ERK signaling pathways were determined by western blotting. In vivo antileukemia effects on $\mathrm{HL}-60 / \mathrm{H} 3$ xenograft model and overall mouse survival outcomes were further analyzed in this study. Results: Emodin dose-dependently induced growth inhibition and apoptotic effects in resistant HL-60/ADR cells in vitro as well as in the HL-60/H3 xenograft models in vivo. Moreover, emodin significantly enhanced chemosensitivity of AML cells to Ara-C, inhibited leukemic cell growth, and improved survival in the mouse xenograft model of AML. Dual targeting of Akt and ERK signaling pathways
\end{abstract}

Y. Chen, D. Gan and Q. Huang contributed equally to this work. 


\section{Cellular Physiology Cell Physiol Biochem 2018;48:2061-2073

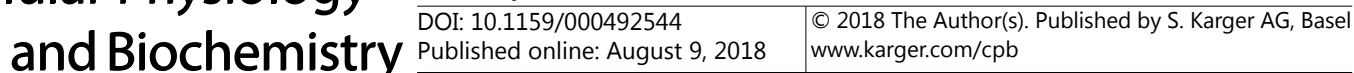 \\ Chen et al.: Emodin and Its Combination with Ara-C Induce Apoptosis in Resistant AML \\ Cells}

might contribute to the anti-leukemia effects on AML cells in vitro and in vivo. Conclusion: Emodin and its combination with Ara- $\mathrm{C}$ may be considered a promising therapeutic approach in $A M L$ and worthy of further investigation.

\section{Introduction}

Acute myeloid leukemia (AML) is a hematopoietic malignancy characterized by immature myeloid cell proliferation and bone marrow failure [1]. Intensive anthracycline and cytarabine (Ara-C)-based combination chemotherapy has been the backbone of AML treatment in recent decades [2,3]. However, AML is still associated with a dismal prognosis [4]. The emergence of multidrug resistance (MDR) to multiple chemotherapeutic agents is a major hurdle in the successful treatment of AML. Discoveries of novel therapeutic agents, which can be used to overcome MDR, become a challenge in the clinic. A lot of traditional Chinese medicine and their active extracts have shown anti-leukemia activities. Many of them have been widely used for the treatment of leukemia patients, such as Taxol, Vincristine, Homoharringtonine and Arsenic Trioxide [5-8].

Emodin (1, 3, 8-trihydroxy-6-methyl-anthraquinone) is a natural anthraquinone compound extracted from various Chinese herbs including Rheum officinale and Polygonam cuspidatum medicine. In vitro and in vivo studies have demonstrated that emodin may be a suitable candidate for cancer treatment [9-13]. A recent report showed that emodin can effectively reverse the resistance of lung cancer H69AR cells to doxorubicin by inhibition epithelialmesenchymal transition [14]. Emodin reverses adriamycin resistance in chronic myelogenous leukemia K562/ADM cells by downregulation of P-gp protein [15]. The effects of emodin and its combination with chemotherapeutic agents on resistant AML cells are unclear. In the present study, we administered emodin alone or combined with Ara-C in both multi-drug resistant AML HL-60/ADR cells in vitro and in a xenograft model of human highly tumorigenic AML HL-60/H3 cells in vivo. We demonstrate that emodin could inhibit proliferation and induce apoptosis in different leukemia cell lines including in HL-60/ADR cells. Of note, emodin at low dose potentially enhanced sensitivities to Ara-C in both HL-60/ADR cells and HL-60/H3 cells. The blockage of Akt and ERK signaling pathway played a critical role for the observed therapeutic effects of emodin in vitro and in vivo. These findings provide new insights into overcoming resistance in AML cells and demonstrate an attractive novel strategy in future treatment of AML.

\section{Materials and Methods}

Chemicals and reagents

Emodin $\left(\mathrm{C}_{15} \mathrm{H}_{10} \mathrm{O}_{5}\right.$, MW: 446.35, HPLC-determined purity > 98\%) was obtained from Nanjing Qingze Medical Technology Company (Nanjing, China). Adriamycin (ADR) was purchased from Pharmacia Italia S.P.A. Cytarabine (Ara-C) was obtained from Zhejiang Hisun Pharmaceutical Company (Taizhou, Zhejiang, China). The preparation and maintenance of the stock solutions of reagents were described previously [13].

\section{Cell lines and cell culture}

The human multidrug resistant AML HL-60/ADR cell line and its parental HL-60 cell line were obtained from the Institute of Hematology, Chinese Academy of Medical Sciences. Human AML cell line (U937), human lymphocytic leukemia and lymphoma cell lines (CEM, Jurkat, Molt-4, CA46) were purchased from CCTCC (China Center for Type Culture Collection, Wuhan, Hubei, China). HL-60 cells were inoculated subcutaneously into nude mice to establish a human leukemia xenograft model. The highly tumorigenic leukemia cell line HL-60/H3 cells were isolated from the HL-60 xenografted tumor cells in nude mice. All leukemia cell lines were routinely cultured in RPMI-1640 medium supplemented with 10\% fetal bovine serum. HL-60/ADR cells were maintained in RPMI-1640 medium with 0.2-0.8 $\mu \mathrm{g} / \mathrm{ml}$ ADR and were grown in ADR-free culture medium at least two weeks for each experiment. 


\section{Cellular Physiology Cell Physiol Biochem 2018;48:2061-2073 \\ \begin{tabular}{ll|l} 
DOI: 10.1159/000492544 & and Biochemistry & $\begin{array}{l}\text { O } 2018 \text { The Author(s). Published by S. Karger AG, Basel } \\
\text { www.karger.com/cpb }\end{array}$ \\
\cline { 2 - 3 }
\end{tabular}}

Chen et al.: Emodin and Its Combination with Ara-C Induce Apoptosis in Resistant AML

Cells

\section{Cell proliferation assay}

Cells were treated in triplicate with emodin alone or in combination with increasing concentrations of Ara-C for $72 \mathrm{~h}$ at $37^{\circ} \mathrm{C}$ Cells were then incubated with $5 \mathrm{mg} / \mathrm{ml} \mathrm{3,4,5-} \mathrm{Dimethylthiazol-2-yl-2,} \mathrm{5-}$ diphenyltetrazolium bromide (MTT) (Sigma, St. Louis, MO, USA) for $4 \mathrm{~h}$. The supernatants were removed and cells were pulsed with $100 \mu \mathrm{l}$ DMSO. The optical density (OD) was measured at $492 / 630 \mathrm{~nm}$ using a spectrophotometer (STAT FAX-2100). The inhibitory rate on cell proliferation was calculated as $\left(1-\mathrm{OD}_{\text {treated }}\right.$ / $\left.\mathrm{OD}_{\text {control }}\right) \times 100 \%$. The half inhibitory concentration $\left(\mathrm{IC}_{50}\right)$ values were obtained by the Logit method.

\section{Assessment of apoptosis by Annexin $V-P E / 7-A A D$ and $A O / E B$ staining}

Briefly, $1.0-2.0 \times 10^{5} / \mathrm{ml}$ cells in RPMI 1640 medium with $10 \%$ fetal bovine serum were plated in 6-well plates. After $24 \mathrm{~h}$ of incubation with emodin, Ara-C, or emodin plus Ara-C, cells were harvested and washed with PBS, and then stained with Annexin V-PE/7-AAD (Becton Dickinson, NJ, USA) according to the manufacturer's instruction. The apoptotic cells were quantified by flow cytometry. For Acridine Orange/ Ethidium Bromide (AO/EB) staining, $5 \mu \mathrm{l}$ of unfixed cells were loaded using $95 \mu \mathrm{l}$ of freshly prepared AO/ EB staining solution $(100 \mu \mathrm{g} / \mathrm{ml})$ and immediately observed under a Nikon fluorescence microscope (Nikon Inc., Japan) within $20 \mathrm{~min}$.

\section{DNA Fragmentation Assay}

HL-60/ADR cells were exposed to different concentrations of emodin for $72 \mathrm{~h}$. Cells were harvested and washed with PBS. DNA extraction was performed according to the manufacturer's protocol. DNA was visualized by Goldview Nucleic Acid Stain on Gel Image Analysis System (Peiqing, JS-380A, Shanghai, China).

\section{Western blot analysis}

HL-60/ADR cells were exposed to emodin at varying concentrations and time points in vitro. Cells were collected and protein was purified after treatment. For the in vivo study, tumor tissues of approximately $100 \mathrm{mg}$ per mouse were minced and homogenized on ice. The tumor tissue protein was purified. Western blotting was performed as described previously $[16,17]$. Quantification of the band densitometry was performed by Quantity One Version 4.6.2 Software (BIO-RAD, Hercules, CA, USA). Primary antibodies against human Procaspase-9, Procaspase-3, Bid, poly (ADP-ribose) polymerase (PARP), p-Akt (Ser473), Akt, p-mTOR(Ser2448), mTOR , p-4E-BP1 (Thr70) and p-p70S6k(Thr389) were obtained from Cell Signaling Technology (Beverly, MA, USA). Bcl-2, Bax, ERK, p-ERK1/2(Thr202/Tyr204) and $\beta$-Actin antibodies were purchased from Santa Cruz Biotechnology (Santa Cruz, CA, USA). Rapamycin was obtained from Calbiochem EMD Millipore Corporation (Billerica, MA, USA). LY294002 and PD98059 were obtained from Sigma-Aldrich Corporation (St. Louis, MO, USA).

\section{In vivo anti-tumor growth model and overall survival outcomes}

BALB/C-nude mice (SPF) were purchased from Shanghai Slac Laboratory Animal Co., Ltd.. All mice were maintained in SPF conditions in the animal facility at Fujian Medical University. Animal studies were performed according to the protocol approved by the Ethics Committee of Institutional Animal Care and Use in Fujian Medical University. Six- to eight-week-old nude mice were subjected to $100 \mathrm{mg} / \mathrm{kg} / \mathrm{d}$ cyclophosphamide by intraperitoneal (ip) injection for two days. Forty-eight hours after preconditioning, around $1.5 \times 10^{7} \mathrm{HL}-60 / \mathrm{H} 3$ cells were subcutaneously injected into the right flank of nude mice. When the tumor volume reached approximately $100 \mathrm{~mm}^{3}$, the tumor-bearing mice were treated with either vehicle alone $(\mathrm{n}=6), 20 \mathrm{mg} / \mathrm{kg}(\mathrm{n}=6), 40 \mathrm{mg} / \mathrm{kg}(\mathrm{n}=6)$ of emodin, or the sequential combination of emodin and Ara-C ( $\mathrm{n}=6,20 \mathrm{mg} / \mathrm{kg}$ emodin treatment prior to $2 \mathrm{mg} / \mathrm{kg}$ Ara-C injection). All mice were administered by i.p. injections once a day for 14 days. Tumor size was measured every 7 days with a caliper (tumor volume $=$ shortest diameter ${ }^{2} \times$ longest diameter/2). Mouse whole blood was collected at $24 \mathrm{~h}$ after the last administration. Tumor tissues and organs were carefully excised. Tumor suppression rate $(\%)=(1-$ mean tumor weight in experimental group/mean tumor weight in control group) $\times 100 \%$.

The experiment was repeated and animals were monitored every day. The survival rate and survival time were evaluated. The endpoint of follow-up for each mouse was determined by the following conditions: lack of response to manual stimulation, immobility, and/or inability to eat or drink. The remaining mice were euthanized at the 70th day after the treatment. 


\section{Cellular Physiology Cell Physiol Biochem 2018;48:2061-2073 \\ \begin{tabular}{ll|l} 
DOI: 10.1159/000492544 & and Biochemistry & $\begin{array}{l}\text { O 2018 The Author(s). Published by S. Karger AG, Basel } \\
\text { www.karger.com/cpb }\end{array}$ \\
\hline
\end{tabular} \\ Chen et al.: Emodin and Its Combination with Ara-C Induce Apoptosis in Resistant AML \\ Cells}

\section{Mouse blood count}

Whole blood of mice from each group was collected into sterile tubes containing $\mathrm{K}_{2}$ EDTA for hematological studies before animals were sacrificed. Peripheral leukocytes, erythrocytes, platelets, and hemoglobin concentration were measured by using an automatic animal blood counter (HEMAVET 950, Drew Scientific Inc, Miami Lakes, USA).

\section{Histopathological examination}

Mice were sacrificed by cervical dislocation after last administration. Main organs, including heart, liver, spleen, lung, kidney, intestine, and tumor tissues isolated from each group were fixed in paraformaldehyde solution, embedded in paraffin, and stained with hematoxylin-eosin. The structure and internal organization were observed by light microscopy.

\section{Electron microscopy observation}

Briefly, approximately $1 \mathrm{~mm}^{3}$ volume of newly isolated tumor tissue was fixed at $4^{\circ} \mathrm{C}$ in $3 \%$ glutaraldehyde solution before treatment with $1 \%$ osmium tetroxide. Samples were washed prior to successive dehydration and emersion in propylene oxide:resin (1:1), followed by resin only. Samples were polymerized before sectioning and staining with lead citrate/uranylacetate for imaging under transmission electron microscopy (Hu-12A, Hitachi, Japan).

\section{Statistical analysis}

Results are presented as mean \pm standard deviation, and statistical comparisons of experimental groups were evaluated by Student's $t$ test using GraphPad Prism (version 5.0). Mouse survival curves were constructed by the KaplanMeier methodology and compared by the log-rank test. $P<0.05$ was considered as significant difference.

\section{Results}

Emodin inhibits proliferation and induces apoptosis in different leukemic cells

MTT assay was used to examine the growth inhibitory effects in eight independent human leukemic cell lines including U937, CEM, Molt-4, Jurkat, CA46, HL-60, HL-60/ $\mathrm{H} 3$, and multidrug resistant HL-60/ADR cells. Emodin inhibits the growth of myeloid leukemia cells as well as that of lymphocytic leukemia cells. The anti-proliferation effects of emodin in various leukemia cell lines were presented in a dose-dependent way (Fig.1A). The IC50 value was between $22.28 \pm 3.07 \mu \mathrm{M}$ and $39.17 \pm$ $1.69 \mu \mathrm{M}$.

\section{KARGER}

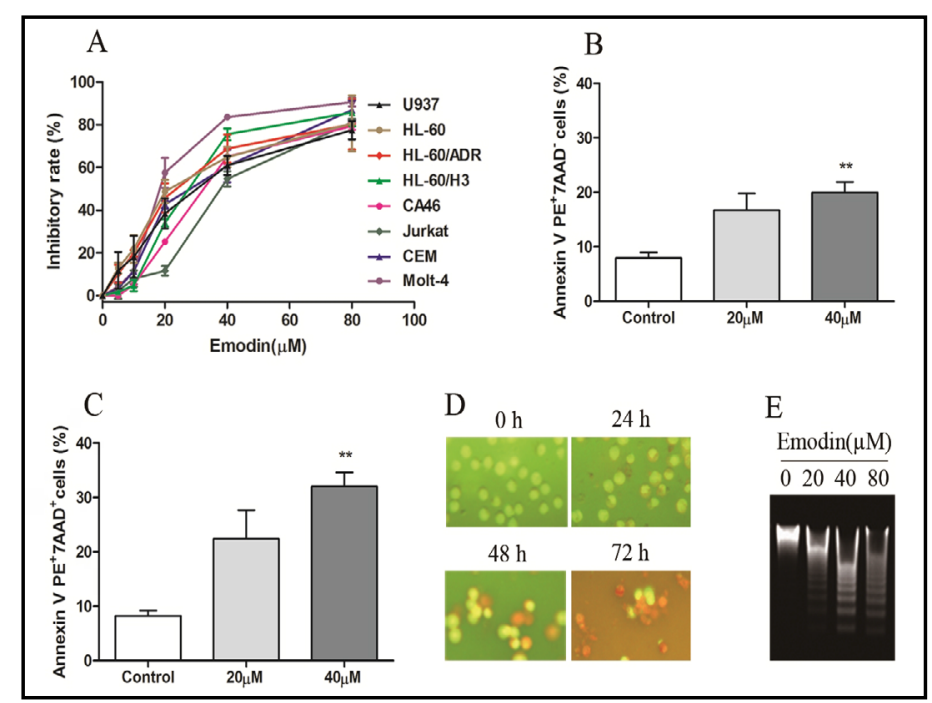

Fig. 1. Emodin inhibits cell proliferation and induces apoptosis in leukemia cells. (A) MTT assay was used to measure the growth inhibition in acute myelogenous leukemia cells (U937, HL-60, HL60/H3 and resistant HL-60/ADR) and human lymphocytic leukemia and lymphoma cells (CEM, Jurkat, Molt-4, CA46). (B, C) HL-60/ ADR cells were treated with increasing doses of emodin for $24 \mathrm{~h}$. Apoptotic cells were determined by Annexin V/7-AAD staining. The data presented as mean \pm SD from three independent experiments. ** $\mathrm{P}<0.01$, vs. control. (D) HL-60/ADR cells were treated with 40 $\mu \mathrm{M}$ emodin for 0-72 $\mathrm{h}$. Cells were harvested, and then stained with Acridine Orange/Ethidium Bromide (AO/EB). Apoptotic cells were verified by fluorescent microscope. (E) HL-60/ADR cells were treated with indicated concentrations of emodin for $72 \mathrm{~h}$. Genomic DNA was purified and subjected to electrophoresis in $1 \%$ agarose gel. 
The apoptotic induction effects of emodin on resistant HL-60/ADR cells were measured. As anticipated, the percentages of total apoptotic HL-60/ADR cells (Annexin-V PE ${ }^{+}$7-AAD ${ }^{+}$) were increased from $8.25 \pm 1.01 \%$ to $22.41 \pm 5.29 \%$ and 32.03 $\pm 2.59 \%$ after $20 \mu \mathrm{M}$ and 40 $\mu \mathrm{M}$ emodin treatment for $24 \mathrm{~h}$, respectively (Fig. 1C). The percentages of early apoptotic cells (Annexin-V $\mathrm{PE}^{+}$7-AAD) were $7.94 \pm$ $1.80 \%, 16.77 \pm 5.26 \%$, and $19.97 \pm 3.35 \%$ in 0,20 , and $40 \mu \mathrm{M}$ emodin treatment groups, respectively (Fig. 1B). The increase in percentage of apoptotic cells induced by emodin was dose-dependent, being significantly higher in the $40 \mu \mathrm{M}$ emodin treatment group in comparison to the treatment group without emodin $(P=0.001)$.

$\mathrm{AO} / \mathrm{EB}$ staining results showed that HL-60/ADR cells in the vehicle control group presented clear cellular and nuclear morphology. However, typical apoptotic nuclei were observed in emodintreated cells, including the occurrence of chromatin condensation, nuclear fragmentation, and cell membrane destruction. The apoptotic morphology change of HL-60/ADR cells positively correlated with the exposure time of $40 \mu \mathrm{M}$ emodin (Fig. 1D). Consistently, the DNA fragmentation assay revealed characteristic ladder patterns in emodin-treated HL-60/ ADR cells. The DNA ladder appeared more evident in high concentration of emodin exposure groups (Fig. 1E).

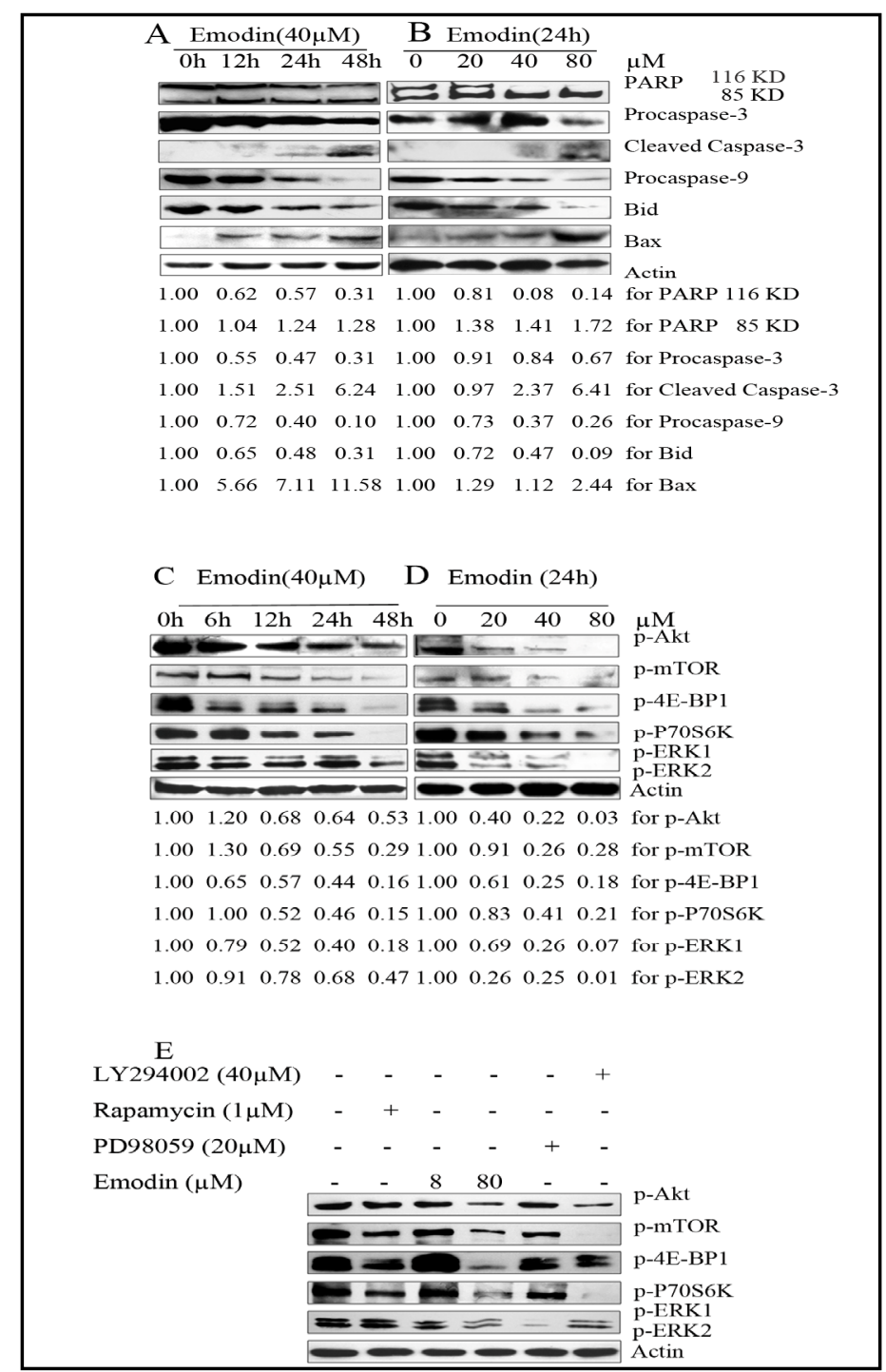

Fig. 2. Emodin activates caspase-dependent apoptotic pathway and inhibits Akt and ERK signaling pathways in HL-60/ADR cells. (A, C) HL-60/ADR cells were treated with $40 \mu \mathrm{M}$ emodin at indicated time points. (B, D) HL-60/ADR cells were treated with increasing doses of emodin for $24 \mathrm{~h}$. Cells were harvested and then proteins were extracted. Western blotting was performed to visualize the expression levels of $116 \mathrm{kDa}$ PARP, $85 \mathrm{kDa}$ PARP, procaspase-3, cleaved caspase-3, procaspase-9, Bid, Bax, phosphorylation of Akt, mTOR, 4E-BP1, p-70S6K, and ERK proteins along with $\beta$-actin as loading controls. The band intensity was quantified. Protein expression levels are represented as percentage change from untreated control levels, which were set to $100 \%$ (1.00). The lower set of numbers indicates the relative protein level. (E) HL-60/ADR cells were treated with emodin $(8$ and $80 \mu \mathrm{M}), \mathrm{LY} 294002(40 \mu \mathrm{M})$, rapamycin $(1.0 \mu \mathrm{M})$ and PD98059 $(20 \mu \mathrm{M})$ for $12 \mathrm{~h}$. Proteins were extracted from harvested cells. Western blot analysis was performed to determine the expression levels of p-Akt, p-mTOR, p-4E-BP1, p-p70S6K, and p-ERK proteins. All experiments were repeated three times. 
Emodin induces activation of the caspase-dependent apoptotic pathway and suppresses activation of the Akt and ERK signaling pathways in HL-60/ADR cells

To explore the underlying mechanisms of emodin-induced apoptosis in HL-60/ADR cells, we further examined several effectors of apoptosis such as the Bcl-2 family and executioner caspases. Western blotting results showed that emodin dramatically reduced the expression levels of Procaspase- 3 and Procaspase- 9 and markedly induced the cleavage of Caspase- 3 and PARP in a dose- and time- dependent manner. Concomitantly, the expression level of Bid, one of the anti-apoptotic protein Bcl-2 family members, was decreased while the proapoptotic Bax protein expression was induced with longer incubation time and higher dose exposure of emodin in HL-60/ADR cells (Fig. 2A and B).

The activation of the Akt signaling pathway is frequently observed in acute leukemia samples and sustains leukemic cell growth $[18,19]$. ERK plays an important role in cell proliferation and differentiation, and its activation is associated with MDR development [2022]. We therefore analyzed whether emodin affects the Akt and ERK signaling pathways. The results demonstrated that emodin dose- and time-dependently abrogated phosphorylation of Akt and mTOR in HL-60/ADR cells. In parallel, emodin also inhibited mTOR downstream targeted proteins p-4E-BP1 and p-p70S6K in HL-60/ADR cells in the same manner (Fig. 2C and D). Of note, emodin remarkably decreased the phosphorylation of ERK both in doseand time-dependent manners. To further confirm the effects of emodin on dual targeting of the Akt and ERK signaling pathways, HL-60/ADR cells were conditioned in parallel with either two different doses of emodin, the PI3K/Akt inhibitor (LY294002), the mTOR inhibitor (Rapamycin), or the MAPK inhibitor (PD98059), respectively. Compared with the untreated group and the lower dose of emodin treatment group, the inhibitory effects on the phosporylation of Akt, mTOR, 4E-BP1 and p70S6K induced by $80 \mu \mathrm{M}$ emodin were as strong

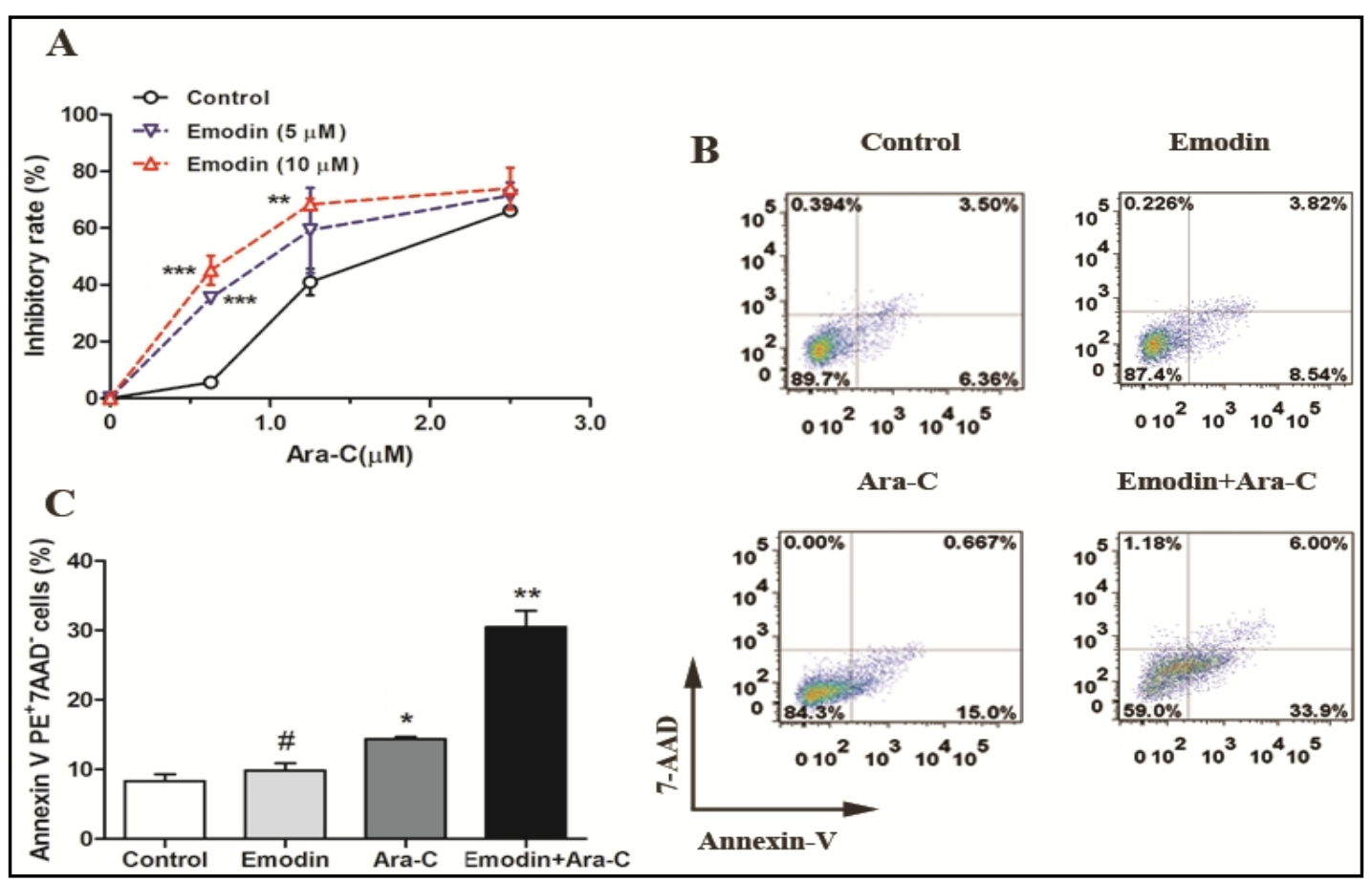

Fig. 3. Emodin enhances sensitivity of HL-60/ADR cells to Ara-C. (A) HL-60/ADR cells were treated with low dose emodin $(5 \mu \mathrm{M}, 10 \mu \mathrm{M})$ in combination with increasing doses of Ara-C for $72 \mathrm{~h}$, respectively. Cell growth inhibition was determined by MTT assay. The value presents as mean \pm SD from three independent experiments $\left({ }^{* *} \mathrm{P}<0.01,{ }^{* * *} \mathrm{P}<0.001\right.$ vs. Ara-C alone). (B, C) HL-60/ADR cells were treated with either 10 $\mu \mathrm{M}$ emodin, $2.0 \mu \mathrm{M}$ Ara-C, alone or in combination. Apoptotic cells were measured by flow cytometry. Dot plots show 7-AAD (y-axis) vs. Annexin-v (x-axis). The results are shown as mean \pm SD of three independent experiments. ( ${ }^{\sharp} \mathrm{P}>0.05,{ }^{*} \mathrm{P}<0.05$ vs. control. ${ }^{* *} \mathrm{P}<0.01$ vs. either emodin or Ara-C alone). 
as those following LY294002 and Rapamycin treatment. Moreover, high concentration of emodin similarly down-regulated the p-ERK protein compared with PD98059 (Fig. 2E). These results indicate the dual targeting of the Akt and ERK pathways is involved in emodinmediated anti-leukemia activity.

\section{Emodin increases sensitivity of HL-60/ADR cells to Ara-C}

Enhancements of the sensitivity of resistant HL-60/ADR cells to Ara-C were also measured by MTT assay. Emodin at $5 \mu \mathrm{M}$ or $10 \mu \mathrm{M}$ alone only induced mild growth inhibition in HL-60/ADR cells. Notably, the administration of emodin along with increasing doses of Ara-C significantly enhanced proliferation inhibition in HL-60/ADR cells. The mean level of growth inhibition was $5.63 \pm 0.52 \%$ and $40.96 \pm 4.69 \%$ in the $0.63 \mu \mathrm{M}$ and $1.25 \mu \mathrm{M}$ Ara-C mono-treament groups, respectively. When $5 \mu \mathrm{M}$ emodin was combined with $0.63 \mu \mathrm{M}$ and $1.25 \mu \mathrm{M}$ Ara-C, the suppression level was increased up to $35.29 \pm 1.41 \%$ and $59.17 \pm 15.07 \%$ in the combination group in HL-60/ADR cells, respectively. When applied higher dose of emodin $(10 \mu \mathrm{M})$ to the $0.63 \mu \mathrm{M}$ and $1.25 \mu \mathrm{M}$ Ara-C mono-treatment group, the inhibitory level was significantly raised to $45.12 \pm 5.15 \%$ and $68.33 \pm 2.02 \%$ in the co-treatment groups, respectively ( $P=0.0006$ and $P=0.002$ vs. Ara-C alone, respectively, Fig. 3A).

To investigate whether low dose emodin has the potential to enhance Ara-C-induced apoptosis in HL-60/ADR cells, the combination treatment of $10 \mu \mathrm{M}$ emodin plus $2.0 \mu \mathrm{M}$ Ara-C was performed in this study. Results showed that only minimal early apoptosis was evident in HL-60/ADR cells in the presence of $10 \mu \mathrm{M}$ emodin for $24 \mathrm{~h}$, which was equivalent to that of the untreated control $(P=0.35)$. However, the percentage of early apoptotic cells dramatically increased up to $30.47 \pm 2.36 \%$ in the co-treatment group, which was 2 -fold higher than that in the Ara-C only-treated group $(P=0.003)$ (Fig. 3B and 3C).

Emodin inhibits xenograft growth and enhances anti-leukemia activities of Ara-C in the HL-60/H3 xenograft model

The anti-leukemic potential of emodin alone or in combination with Ara-C in vivo was tested using a HL-60/H3 xenograft model in nude mice. As shown in Fig. 4A-C, the growth of HL-60/H3 tumors in each conditioning group was remarkably suppressed by comparison with that in the vehicle control group after 14 days of treatment. The average tumor volume of the combination group was $0.37 \pm 0.05 \mathrm{~cm}^{3}(\mathrm{n}=6)$, which was significantly smaller than that in the vehicle alone $(\mathrm{n}=6)$ and $20 \mathrm{mg} / \mathrm{kg}(\mathrm{n}=6)$ or $40 \mathrm{mg} / \mathrm{kg}(\mathrm{n}=6)$ of emodin- or Ara-C-treated groups $(n=6)$. Twenty-four hours after the last administration, tumor tissues in each group were carefully excised and weighed. The mean tumor weight in the vehicle control group was $3.16 \pm 0.88 \mathrm{~g}(\mathrm{n}=6)$. Emodin combined with Ara-C-treated mice displayed dramatic inhibition of leukemia cell expansion. The mean tumor weight in the combination group was $0.29 \pm 0.07 \mathrm{~g}(\mathrm{n}=6)$, which was significantly lower than that in the emodin, Ara-C, and vehicle control groups. The tumor inhibitory rate was $32.2 \%, 52.5 \%$ and $77.4 \%$ in $20 \mathrm{mg} / \mathrm{kg}$ emodin, $40 \mathrm{mg} / \mathrm{kg}$ emodin and Ara-C alone groups, respectively. However, the combination of emodin and Ara-C presented much more inhibitory effects on mouse leukemia xenograft model. The tumor inhibition was as high as $90.9 \%$ following emodin plus Ara-C administration. These results provide in vivo evidence of AML cells in response to emodin treatment. The combination of the conventional drug Ara-C and the novel compound emodin may exert synergistic anti-leukemic effects.

\section{Emodin combined with Ara-C induces apoptosis in vivo via inactivation of the Akt and ERK} pathways

The ultrastructural changes in leukemia cells in the xenograft model were further assessed under the microscope. Emodin in combination with Ara-C treatment triggered more apoptotic cells in the tumor tissues. These cells exhibited morphological features of cell apoptosis, including nuclear condensation, nuclear fragmentation, and apoptotic body formation. Tumor cells from Ara-C-treated mice displayed necrosis phenotype features, such as disruption of ultrastructural integrity and nuclear degeneration. By contrast, HL-60/H3 
Fig. 4. Emodin combined with Ara-C treatment leads to growth inhibition and apoptosis induction of HL-60/H3 cells in xenograft mice. The nude mice with HL-60/ H3 xenografts were randomly divided into five groups and intraperitoneally given injection of emodin (20 mg/kg), emodin (40 $\mathrm{mg} / \mathrm{kg}$ ), Ara-C (2 mg/kg) and the sequential combination $(20 \mathrm{mg} /$ $\mathrm{kg}$ emodin treatment prior to 2 $\mathrm{mg} / \mathrm{kg}$ Ara-C injection), or vehicle once a day for a period of 2 weeks. Tumor size was measured once a week with a caliper (tumor volume $=$ shortest diameter $^{2} \times$ longest diameter/2). The tumor volumes are expressed as mean \pm SD $(n=6$ per group). (A) The curves of tumor sizes. (B, C) The tumor weight was measured after tumor tissues were excised. Tumor suppression rate $(\%)=(1-$ mean tumor weight in experimental group/mean tumor weight in control group) $\times 100 \%$. ${ }^{\#} \mathrm{P}>0.05, \quad{ }^{* *} \mathrm{P}<0.01, \quad * * * \mathrm{P}<0.001$ vs. control, $* \mathrm{P}<0.05$ vs. either Ara-C or $20 \mathrm{mg} / \mathrm{kg}$ emodin group. (D) Ultrastructural changes of

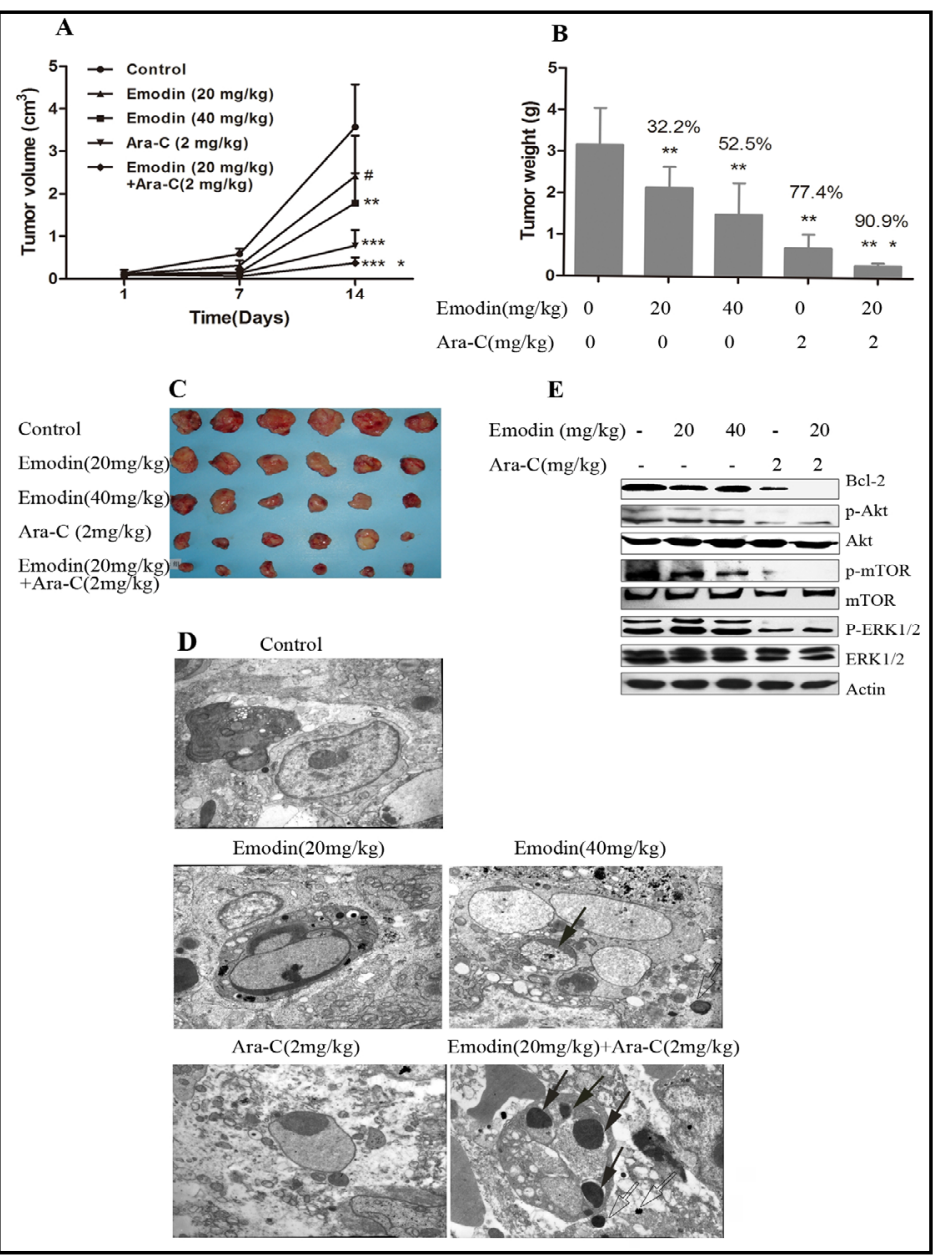
leukemic cells in each group were observed by electron microscope after the treatment. Control (magnification: 6300x). Emodin (20 mg/ $\mathrm{kg}$ ) (magnification: $6300 \times$ ). Emodin (40 mg/kg) (magnification: 6300x). Ara-C (2 mg/kg) (magnification: $8000 \times)$. Emodin $(20 \mathrm{mg} / \mathrm{kg})+$ Ara-C $(2 \mathrm{mg} / \mathrm{kg}$ ) (magnification: $8000 \times)$. Clear arrow: apoptotic body. Solid arrow: nucleus condensation. (E) Western blot was used to analyze the inhibitory effects on Bcl-2 expression, Akt and ERK activation in HL-60/H3 xenograft cells following different administration.

cells maintaining ultrastructural integrity were densely distributed in the vehicle xenograft tumor tissues (Fig. 4D).

The molecular mechanism underlying susceptibility to apoptosis of HL-60/H3 cells in vivo was analyzed. Western blotting results showed that the combination of $20 \mathrm{mg} / \mathrm{kg}$ emodin and $2 \mathrm{mg} / \mathrm{kg}$ Ara-C resulted in remarkable down-regulation of expression levels of p-Akt, p-mTOR and p-ERK. Consistently, anti-apoptotic Bcl-2 protein in the tumor tissues was also markedly inhibited following combination treatment (Fig. 4E). These findings further verified that emodin plus Ara-C might exert more efficient anti-leukemic effects. Both the Akt and ERK pathways were identified as potential therapeutic targets following co-treatment.

\section{Histopathological and hematological examination}

In Fig. 5A, HL-60/H3 cells in subcutaneous tumor tissues in the vehicle control group were round or elliptical and of different sizes with large stained nuclei. Few tumor cells were found in tumor tissues from differently conditioned mice exhibiting morphological changes, such as cell shrinkage, nuclear condensation, or remaining the nude nuclear. Some erythrocytes were present on the tissue sections from conditioned mice. Focal necrosis of tumor cells was observed in the higher dose emodin treatment group. The increasing

\section{KARGER}




\section{Cellular Physiology \begin{tabular}{l|l} 
and Biochemistry Published onlIne: August 9, 2018 & $\begin{array}{l}\text { @) } 2018 \text { The Author(s). Published by S. Karger AG, Basel } \\
\text { www.karger.com/cpb }\end{array}$ \\
\hline
\end{tabular} \\ Chen et al.: Emodin and Its Combination with Ara-C Induce Apoptosis in Resistant AML}

Cells

Fig. 5. Histopathological and hematological examination results in xenograft models. (A) Hematoxylin-eosin stained of tumor tissue sections from representative control and treated mice (magnification: $\times 200$ ). (B) Mouse blood count. Peripheral leukocyte, erythrocyte, hemoglobin and platelet concentration from mouse whole blood were measured by using an automatic animal blood counter. Data are presented as mean \pm SD ( $\mathrm{n}=6$ per group). ${ }^{*} \mathrm{P}<0.05,{ }^{* *} \mathrm{P}<0.01$ vs. control. ns, no statistical significance.

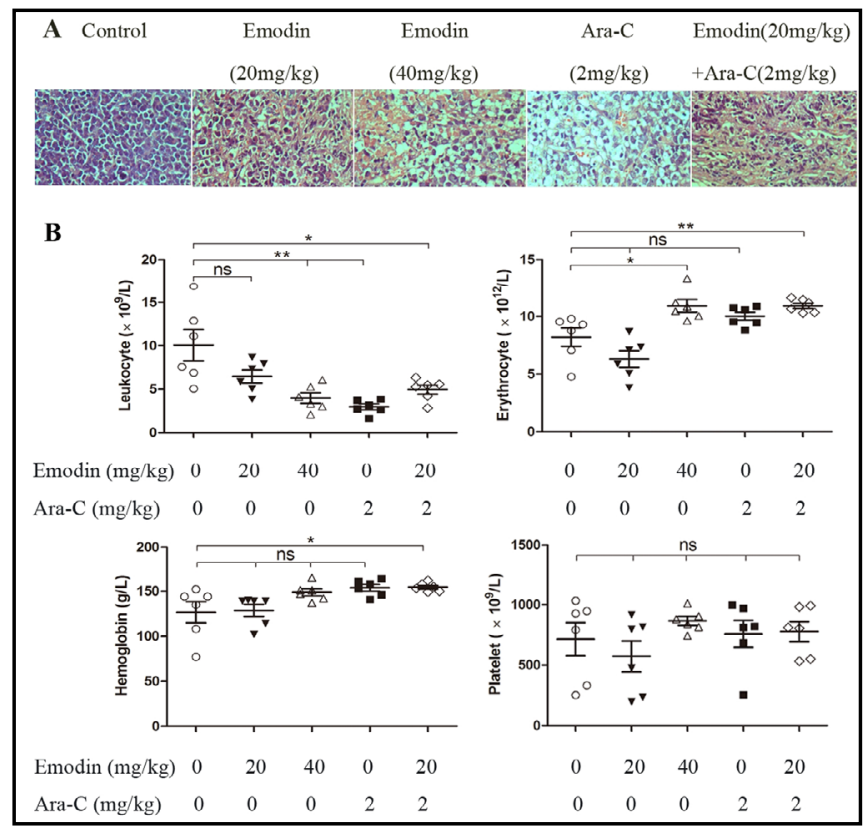

Fig. 6. Emodin and its combination with Ara-C improve AML xenograft mouse survival. Mouse xenograft models of AML were monitored every day after initial administration. The survival rate and survival time were evaluated in each group. ${ }^{*} \mathrm{P}<0.05,{ }^{* *} \mathrm{P}<0.01$ vs. control.

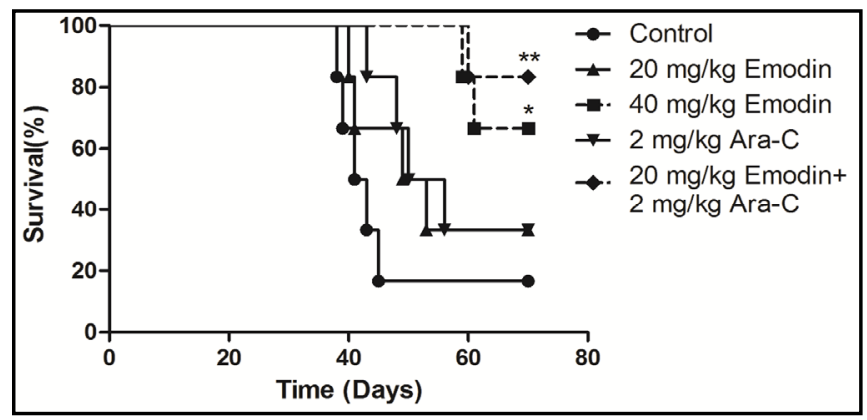

numbers of fibroblast cells and collagen fiber deposition were frequently observed in the tumor tissues from combination treatment mice.

Hematological examinations showed that leukocyte counts were only modestly decreased at low dose emodin alone $(P=0.09)$, but significantly decreased at either high dose emodin, Ara-C alone, or low dose emodin plus Ara-C when compared with those of vehicle control mice. There were statistically significant increases in both erythrocyte counts and hemoglobin levels following emodin combined Ara-C treatment. No significant effects on platelet counts were found in any regimen (Fig. 5B). After the last administration, the important organs including the heart, liver, spleen, lung, kidney, and intestine were also well excised from the xenograft models in each group. There were no significant histological changes in any organ from the treated mice (data not shown).

\section{Survival analysis}

The different regimens were well tolerated by the HL-60/H3 xenograft nude mice, and no significant side-effects were found during the 14 day administration. As shown in Fig. 6 , all of the animals survived at the 35th day after the initial administration. However, the survival rate was less than $50 \%$ at the 70 th day, which was $16.7 \%(1 / 6), 33.3 \%(2 / 6)$, and $33.3 \%$ (2/6)in the vehicle control, $20 \mathrm{mg} / \mathrm{kg}$ emodin, and $2 \mathrm{mg} / \mathrm{kg}$ Ara-C groups, respectively. In comparison, more than half of the mice remained alive in the $40 \mathrm{mg} / \mathrm{kg}$ emodin group and the combination group at the end of 70 day observation (survival rate: $66.7 \%$ and $83.3 \%$, respectively). The log rank test results showed that both the $40 \mathrm{mg} / \mathrm{kg}$ emodin and 
emodin plus Ara-C regimens significantly reduced the HL-60/H3 leukemia burden in mice, particularly noted as improved survival when compared with the vehicle control $(P=0.020$ and $P=0.010$, respectively).

\section{Discussion}

Plant-derived natural products have garnered considerable attention in recent years due to the remarkable pharmacological properties in hematological malignancies $[5,9,23]$. Here, we presented the anti-leukemic effects of emodin and its combination with Ara-C on multidrug-resistant HL-60/ADR cells. And we also demonstrated the first report about the in vivo therapeutic effects based on a murine xenograft model of AML using emodin and its combination treatment regimen. In addition, we further confirmed that the dual suppression of constitutive activation of the Akt and ERK pathways might be involved in growth inhibition in AML cells by emodin.

Multidrug resistance (MDR), by which leukemia cells are resistant to multiple chemotherapeutic agents, is a serious problem correlated with poorer clinical outcome in acute leukemia patients. Novel drugs, which could overcome MDR, are of great importance for the treatment of AML patients. Emodin, a natural anthraquinone compound extracted from traditional Chinese medicine, has been shown to have multiple anti-tumor activities [9-15]. The administration of emodin in pregnant mice has been previously reported, which indicated its high safety [24]. Liu et al. showed that emodin could be used as a sensitizer in the gemcitabine-resistant pancreatic cancer cells [25]. HL-60/ADR cells overexpressed multidrug resistance-associated protein (MRP1) are highly resistant to different chemotherapeutic agents $[13,26]$. Our results showed that emodin dose- dependently inhibited proliferation and induced apoptosis in HL-60/ADR cells. Notably, the IC50 value of emodin in resistant HL-60/ADR cells was similar to that in sensitive HL-60 cells. So we designed and synthesized a series of derivatives based on the anthraquinone structure of emodin. Similar pharmacological effects as those induced by emodin were found on resistant leukemia cells. One of the most important mechanisms was due to the unique anthraquinone structure of emodin, which facilitates the capture and delivery of electrons from the electron respiratory chain to oxygen to enhance the generation of reactive oxygen species (ROSs) in leukemia cells, including in those with the MDR phenotype. Emodin as ROS-inducer involved in the process of tumor cell growth suppression and apoptosis has been explored in previous studies $[9,27]$.

Daunomycin (DNR) in combination with Ara-C (DA regimen) was the typical regimen for induction remission in AML over the last decades, and the overall 5-year survival remains poor, being $<30 \%[28,29]$. Recent regimen improvements include the replacement of DNR with the other anthracycline agents and the dose adjustment of Ara-C. In this study, we replaced DNR with the traditional Chinese medicine emodin, which has similar anthraquinone chemo-structure. We found that low dose emodin could significantly enhance the sensitivity of resistant HL-60/ADR cells to Ara-C. The percentage of apoptotic cells markedly increased up to more than 2-fold compared to single Ara-C-treated cells. These data indicate that emodin may be a novel inducer of apoptosis and a promising candidate as a chemo-sensitizer for drug resistant AML cells.

Cha et al. in M. D. Anderson Cancer Center showed that emodin could directly target androgen receptor (AR) to suppress prostate cancer cell growth in vitro and prolong the survival of C3 (1)/SV40 transgenic mice [30]. A recent study also showed that emodin may suppress hepatocellular carcinoma growth and improve liver and kidney function in experimental mice without an obvious change in body weight, indicating that emodin may be an effective and safe drug for the treatment of hepatocellular carcinoma [31]. To see whether emodin has the potential to improve AML therapy in vivo, we established an AML xenograft mouse model with highly tumorigenic leukemia HL-60/H3 cells. As we know, the DA regimen is widely used in AML therapy in the clinic. In the in vivo study, we examined emodin

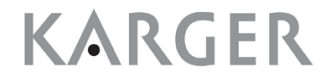




\section{Cellular Physiology Cell Physiol Biochem 2018;48:2061-2073 \\ \begin{tabular}{l|l|l} 
DOI: 10.1159/000492544 & and Biochemistry Published online: August 9, 2018 & $\begin{array}{l}\text { O } 2018 \text { The Author(s). Published by S. Karger AG, Basel } \\
\text { www.karger.com/cpb }\end{array}$
\end{tabular} \\ Chen et al.: Emodin and Its Combination with Ara-C Induce Apoptosis in Resistant AML \\ Cells}

and Ara-C effects to AML. The tumor growth in HL-60/H3 xenograft mice was significantly suppressed in an emodin dose-dependent manner after daily injection of emodin for 14 days. Importantly, the regimen of emodin plus Ara-C presented the best anti-leukemic effects in the HL-60/H3 xenograft mice. More apoptotic leukemia cells were induced by the combination therapy. Moreover, emodin administration was well tolerated by the nude mice, and no severe adverse effects were shown in hematological and histopathological examinations. Survival data in our study demonstrated that high dose emodin could increase the survival rates of HL-60/H3 xenograft mice. It presented better therapeutic effect on reducing tumor burden when low dose emodin was administered with low dose Ara-C, and significantly improved the mouse survival. An in vivo xenograft chemotherapy model might show physiologically relevant responses to the drugs that parallel what is seen in the clinic. Based on the available data, this is the first study to demonstrate the in vivo therapeutic relevance of emodin in a murine xenograft model of AML. The treatment regimen using combined emodin and Ara-C administration may be an appealing strategy for AML therapy.

The constitutive activation of the Akt pathway plays a critical role in the progression of leukemia cases $[18,19]$. Akt activation indirectly promotes transcription of antiapoptotic genes, while it directly phosphorylates the downstream target, mTOR. Brown et al. showed that emodin and docosahexaenoic acid (DHA) potently increase arsenic trioxide interferon- $\alpha$-induced cell death of HTLV-I-transformed cells by generation of ROSs and inhibition of Akt and AP-1(Jun D and JAB1), while the administration did not significantly change the activities of the normal peripheral blood mononuclear cells (PBMCs)[9]. It has been reported that ERK activation is associated with the MDR development [20-22,32]. Whether emodin and its combination therapy affect the activation of Akt and ERK was also addressed in this study. Western blot results showed that the activation of signaling molecules, such as p-Akt, p-mTOR and p-ERK1/2 in HL-60/ADR cells was markedly suppressed by emodin in a time- and dose-dependent pattern. The blocking activation of Akt and ERK of emodin in HL-60/ADR cells was further confirmed by comparison with PI3K/Akt inhibitor LY294002, mTOR inhibitor rapamycin, and MAPK inhibitor PD98059. Moreover, we also found the phosphorylation of both Akt and ERK were significantly abrogated in the xenograft model of AML following emodin plus Ara-C administration. Low dose Ara-C alone did not affect the activation of Akt and ERK, which was consistent with the conclusions previously reported by Sampath Olsen [33]. Together, our in vitro and in vivo experimental results demonstrate that anti-proliferative/pro-apoptotic effects of emodin are mediated at least in part through the dual abrogation of the Akt and ERK signaling pathways in AML cells. Leukemia stem cells (LSCs) are associated with chemotherapy resistance and AML relapse [34-36]. Strategies for the eradication of LSCs may efficiently prevent the recurrence of AML. Thus, it is worthwhile to further investigate whether emodin and its derivatives may target LSCs.

Overall, these findings indicate that emodin and its combination with Ara-C, as a promising new therapeutic paradigm, may elicit more robust responses and provide a novel strategy for AML treatment.

\section{Acknowledgements}

This work was supported by Construction Project of Fujian Medical Center of Hematology (Min201704), National and Fujian Provincial Key Clinical Specialty Discipline Construction Program, National Natural Science Foundation of China $(81500158,81470326)$, Fujian Provincial Natural Science Foundation (2015J05152), Fujian Provincial Medical Innovation Project (2015-CX-14), the Program of New Century Excellent Talents in Fujian Province University (2016B032), Joint Research Project of Health and Education of Fujian Province(WKJ 2016-2-06), and Joint Funds for the Innovation of Science and Technology, Fujian province (2016Y9029, 2016Y9032). 


\section{Cellular Physiology Cell Physiol Biochem 2018;48:2061-2073

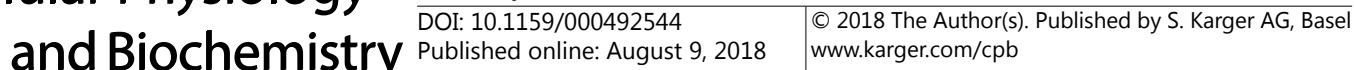 and Bloct.: Emodin and Its Combination with Ara-C Induce Apoptosis in Resistant AML \\ Cells}

\section{Disclosure Statement}

The authors declare no competing financial interests.

\section{References}

1 Lowenberg B, Downing JR, Burnett A: Acute myeloid leukemia. N Engl J Med 1999;341:1051-1062.

$>2$ Roboz GJ: Novel approaches to the treatment of acute myeloid leukemia. Hematology Am Soc Hematol Educ Program 2011;2011:43-50.

-3 Marin JJ, Briz O, Rodriguez-Macias G, Diez-Martin JL, Macias RI: Role of drug transport and metabolism in the chemoresistance of acute myeloid leukemia. Blood Rev 2016;30:55-64.

-4 Schiller GJ: High-risk acute myelogenous leukemia: treatment today ... and tomorrow. Hematology Am Soc Hematol Educ Program 2013;2013:201-208.

5 Chen H, Gao Y, Wu J, Chen Y, Chen B, Hu J, Zhou J: Exploring therapeutic potentials of baicalin and its aglycone baicalein for hematological malignancies. Cancer Lett 2014;354:5-11.

6 Platzbecker U, Avvisati G, Cicconi L, Thiede C, Paoloni F, Vignetti M, Ferrara F, Divona M, Albano F, Efficace F, Fazi P, Sborgia M, Di Bona E, Breccia M, Borlenghi E, Cairoli R, Rambaldi A, Melillo L, La Nasa G, Fiedler $\mathrm{W}$, et al.: Improved outcomes with retinoic acid and arsenic trioxide compared with retinoic acid and chemotherapy in non-high-risk acute promyelocytic leukemia: Final results of the randomized ItalianGerman APL0406 trial. J Clin Oncol 2017;35:605-612.

$>7$ Jin J, Wang JX, Chen FF, Wu DP, Hu J, Zhou JF, Hu JD, Wang JM, Li JY, Huang XJ, Ma J, Ji CY, Xu XP, Yu K, Ren HY, Zhou YH, Tong Y, Lou YJ, Ni WM, Tong HY, et al.: Homoharringtonine-based induction regimens for patients with de-novo acute myeloid leukaemia: a multicentre, open-label, randomised, controlled phase 3 trial. Lancet Oncol 2013;14:599-608.

-8 Kothari A, Hittelman WN, Chambers TC: Cell cycle-dependent mechanisms underlie vincristine-induced death of primary acute lymphoblastic leukemia cells. Cancer Res 2016;76:3553-3561.

-9 Brown M, Bellon M, Nicot C: Emodin and DHA potently increase arsenic trioxide interferon-alpha-induced cell death of HTLV-I-transformed cells by generation of reactive oxygen species and inhibition of Akt and AP-1. Blood 2007;109:1653-1659.

10 Wei WT, Chen H, Ni ZL, Liu HB, Tong HF, Fan L, Liu A, Qiu MX, Liu DL, Guo HC, Wang ZH, Lin SZ: Antitumor and apoptosis-promoting properties of emodin, an anthraquinone derivative from Rheum officinale Baill, against pancreatic cancer in mice via inhibition of Akt activation. Int J Oncol 2011;39:1381-1390.

11 Subramaniam A, Shanmugam MK, Ong TH, Li F, Perumal E, Chen L, Vali S, Abbasi T, Kapoor S, Ahn KS, Kumar AP, Hui KM, Sethi G: Emodin inhibits growth and induces apoptosis in an orthotopic hepatocellular carcinoma model by blocking activation of STAT3. Br J Pharmacol 2013;170:807-821.

$\checkmark 12$ Liu H, Gu LB, Tu Y, Hu H, Huang YR, Sun W: Emodin ameliorates cisplatin-induced apoptosis of rat renal tubular cells in vitro by activating autophagy. Acta Pharmacol Sin 2016;37:235-245.

13 Chen Y, Li J, Hu J, Zheng J, Zheng Z, Liu T, Lin Z, Lin M: Emodin enhances ATRA-induced differentiation and induces apoptosis in acute myeloid leukemia cells. Int J Oncol 2014;45:2076-2084.

14 Ying Y, Qingwu L, Mingming X, Zhenju S, Chaoyang T, Zhengang T: Emodin: One main ingredient of Shufeng Jiedu capsule reverses chemoresistance of lung cancer cells through inhibition of EMT. Cell Physiol Biochem 2017;42:1063-1072.

15 Min H, Niu M, Zhang W, Yan J, Li J, Tan X, Li B, Su M, Di B, Yan F: Emodin reverses leukemia multidrug resistance by competitive inhibition and downregulation of P-glycoprotein. PLoS One 2017;12:e0187971.

16 Hu J, Lin M, Liu T, Li J, Chen B, Chen Y: DIGE-based proteomic analysis identifies nucleophosmin/B23 and nucleolin C23 as over-expressed proteins in relapsed/refractory acute leukemia. Leuk Res 2011;35:10871092.

17 Wang L, Chen B, Lin M, Cao Y, Chen Y, Chen X, Liu T, Hu J: Decreased expression of nucleophosmin/B23 increases drug sensitivity of adriamycin-resistant Molt-4 leukemia cells through mdr-1 regulation and Akt/ mTOR signaling. Immunobiology 2015;220:331-340. 


\section{Cellular Physiology Cell Physiol Biochem 2018;48:2061-2073 \begin{tabular}{ll|l} 
DOI: 10.1159/000492544 & $\begin{array}{l}O \text { 2018 The Author(s). Published by S. Karger AG, Basel } \\
\text { www.karger.com/cpb }\end{array}$
\end{tabular} and Biochemistry \\ Chen et al.: Emodin and Its Combination with Ara-C Induce Apoptosis in Resistant AML}

Cells

18 Tamburini J, Elie C, Bardet V, Chapuis N, Park S, Broet P, Cornillet-Lefebvre P, Lioure B, Ugo V, Blanchet O, Ifrah N, Witz F, Dreyfus F, Mayeux P, Lacombe C, Bouscary D: Constitutive phosphoinositide 3-kinase/Akt activation represents a favorable prognostic factor in de novo acute myelogenous leukemia patients. Blood 2007;110:1025-1028.

19 Martelli AM, Evangelisti C, Chiarini F, McCubrey JA: The phosphatidylinositol 3-kinase/Akt/mTOR signaling network as a therapeutic target in acute myelogenous leukemia patients. Oncotarget 2010;1:89-103.

-20 McCubrey JA, Steelman LS, Chappell WH, Abrams SL, Wong EW, Chang F, Lehmann B, Terrian DM, Milella M, Tafuri A, Stivala F, Libra M, Basecke J, Evangelisti C, Martelli AM, Franklin RA: Roles of the Raf/MEK/ ERK pathway in cell growth, malignant transformation and drug resistance. Biochim Biophys Acta 2007;1773:1263-1284.

-21 Chen T, Wang C, Liu Q, Meng Q, Sun H, Huo X, Sun P, Peng J, Liu Z, Yang X, Liu K: Dasatinib reverses the multidrug resistance of breast cancer MCF-7 cells to doxorubicin by downregulating P-gp expression via inhibiting the activation of ERK signaling pathway. Cancer Biol Ther 2015;16:106-114.

-22 Wang Q, Zou J, Zhang X, Mu H, Yin Y, Xie P: Glucosylceramide synthase promotes Bcl-2 expression via the ERK signaling pathway in the K562/A02 leukemia drug-resistant cell line. Int J Hematol 2014;100:559566.

23 Trivedi R, Muller GA, Rathore MS, Mishra DP, Dihazi H: Anti-Leukemic Activity of Shikonin: Role of ERP57 in Shikonin Induced Apoptosis in Acute Myeloid Leukemia. Cell Physiol Biochem 2016;39:604-616.

24 Jahnke GD, Price CJ, Marr MC, Myers CB, George JD: Developmental toxicity evaluation of emodin in rats and mice. Birth Defects Res B Dev Reprod Toxicol 2004;71:89-101.

25 Liu DL, Bu H, Li H, Chen H, Guo HC, Wang ZH, Tong HF, Ni ZL, Liu HB, Lin SZ: Emodin reverses gemcitabine resistance in pancreatic cancer cells via the mitochondrial apoptosis pathway in vitro. Int J Oncol 2012;40:1049-1057.

-26 Walter RB, Raden BW, Hong TC, Flowers DA, Bernstein ID, Linenberger ML: Multidrug resistance protein attenuates gemtuzumab ozogamicin-induced cytotoxicity in acute myeloid leukemia cells. Blood 2003;102:1466-1473.

27 Dong X, Fu J, Yin X, Qu C, Yang C, He H, Ni J: Induction of apoptosis in HepaRG cell line by aloe-emodin through generation of reactive oxygen species and the mitochondrial pathway. Cell Physiol Biochem 2017;42:685-696.

28 Cancer Genome Atlas Research N, Ley TJ, Miller C, Ding L, Raphael BJ, Mungall AJ, Robertson A, Hoadley K, Triche TJ, Jr., Laird PW, Baty JD, Fulton LL, Fulton R, Heath SE, Kalicki-Veizer J, Kandoth C, Klco JM, Koboldt DC, et al.: Genomic and epigenomic landscapes of adult de novo acute myeloid leukemia. N Engl J Med 2013;368:2059-2074.

29 Burnett A, Wetzler M, Lowenberg B: Therapeutic advances in acute myeloid leukemia. J Clin Oncol 2011;29:487-494.

-30 Cha TL, Qiu L, Chen CT, Wen Y, Hung MC: Emodin down-regulates androgen receptor and inhibits prostate cancer cell growth. Cancer Res 2005;65:2287-2295.

-31 Lin W, Zhong M, Yin H, Chen Y, Cao Q Wang C, Ling C: Emodin induces hepatocellular carcinoma cell apoptosis through MAPK and PI3K/AKT signaling pathways in vitro and in vivo. Oncol Rep 2016;36:961967.

-32 Zhao YY, Yu L, Liu BL, He XJ, Zhang BY: Downregulation of P-gp, Ras and p-ERK1/2 contributes to the arsenic trioxide-induced reduction in drug resistance towards doxorubicin in gastric cancer cell lines. Mol Med Rep 2015;12:7335-7343.

-33 Sampath D, Cortes J, Estrov Z, Du M, Shi Z, Andreeff M, Gandhi V, Plunkett W: Pharmacodynamics of cytarabine alone and in combination with 7-hydroxystaurosporine (UCN-01) in AML blasts in vitro and during a clinical trial. Blood 2006;107:2517-2524.

-34 Long B, Wang LX, Zheng FM, Lai SP, Xu DR, Hu Y, Lin DJ, Zhang XZ, Dong L, Long ZJ, Tong XZ, Liu Q: Targeting GLI1 suppresses cell growth and enhances chemosensitivity in $\mathrm{CD}_{3} 4^{+}$enriched acute myeloid leukemia progenitor cells. Cell Physiol Biochem 2016;38:1288-1302.

-35 Gentles AJ, Plevritis SK, Majeti R, Alizadeh AA: Association of a leukemic stem cell gene expression signature with clinical outcomes in acute myeloid leukemia. JAMA 2010;304:2706-2715.

-36 Richard-Carpentier G, Sauvageau G: Bringing a leukemic stem cell gene signature into clinics: Are we there yet? Cell Stem Cell 2017;20:300-301. 